\title{
Thermal Stress Analysis of BOF Accounting for Friction Force Experimentally Measured
}

\author{
Yuta HINO, ${ }^{11}$ Yoshisato KIYOTA ${ }^{1)}$ and Yoshimitsu HATTOR ${ }^{21}$ \\ 1) Slag and Refractories Department, Steel Research Laboratory, JFE Steel Corporation, 1 Kawasaki-cho, Chuo-ku, Chiba 260- \\ 0835 Japan. $\quad$ 2) JFE Sekkei Ltd., 1-1 Kawasakidori, Mizushima, Kurashiki 712-8074 Japan.
}

(Received on March 31, 2010; accepted on May 13, 2010)

\begin{abstract}
Thermal stress simulations by the finite element method (FEM) are widely used to analyze refractory damage caused by mechanical factors. Issues studied by FEM simulation of refractories include joint conditions, and friction between refractories. The static friction coefficient and dynamic friction coefficient between $\mathrm{MgO}-\mathrm{C}$ refractories with various surface conditions were measured. And the effects of joint conditions and friction force on the thermal stress analysis of the refractory lining in the barrel and cone of the converter were investigated numerically. The results are summarized as follows.

(1) The friction coefficient between refractories that had various surface conditions was measured. As a result, a static friction coefficient of 0.52 and a dynamic friction coefficient of 0.42 were obtained for the friction working between the surfaces of baked $\mathrm{MgO}-\mathrm{C}$ refractories.

(2) It is necessary to consider friction force in the thermal stress analysis because local abnormal increases in stress occur, corresponding to large displacement of the bricks. Considering the situation of wear brick in operation, it was appropriate to apply for the value of baked brick as a friction coefficient.

(3) The effect of the joint conditions used here, which were contact element, gap element, and anisotropy of mechanical property, on the results of calculations of thermal stress by FEM was comparatively smaller than that of friction force when friction force was considered. If the logic of displacement and stress transmission on two bricks is considered, contact element is appropriate from the viewpoint of stress transmission.
\end{abstract}

KEY WORDS: thermal stress; joint; friction coefficient; converter.

\section{Introduction}

It is generally known that the furnace life of steelmaking vessels is determined by damage of the refractories used in the vessel lining. The causes of damage of the refractory linings of steelmaking equipment such as the converter, ladle, etc. can be divided into the following two factors: (1) chemical factors such as the reaction between the steelmaking slag and refractories and (2) mechanical factors such as structural spalling, thermal spalling, and mechanical spalling. Thermal stress simulations by the finite element method (FEM) are widely used to analyze refractory damage caused by mechanical factors. ${ }^{1-6)}$ Issues studied by FEM simulation of refractories include the critical thermal conditions for refractories, high-temperature properties of materials, joint conditions, and friction between refractories. In particular, joint conditions are an important factor because they affect the analytical results, but these conditions differ significantly depending on the model. ${ }^{7-10)}$ In previous studies, the following methods were adopted as joint conditions: (a) method of modelling the absorption of thermal expansion linearly, (b) method in which a value for displacement volume was established and force was transmitted when displacement proceeded beyond the established value, (c) method in which the spring constant was assumed and changed as an appropriate value, and others. However, in these studies, the joint condition was different from study to study, and the synthetic analytical condition has not been discussed. Moreover, there have been no reports of FEM considering friction force. Although a limited number of reports have examined the friction coefficient in architectural brick and mortar construction, ${ }^{11)}$ few reports have discussed the friction force and friction coefficients between refractories in iron- and steelmaking processes.

Focusing on these points, in this study, experiments were undertaken to obtain the friction coefficients between $\mathrm{MgO}-\mathrm{C}$ refractories with various surface conditions. Thermal stress was simulated using the results of measurements of the friction coefficients, and the effects of joint conditions and friction force on the calculated thermal stress distribution in the barrel and cone area of the converter were examined.

\section{Experiment}

\subsection{Experimental Procedure}

The friction coefficients of refractories were measured using the experimental apparatus shown in Fig. 1. The $\mathrm{MgO}-\mathrm{C}$ brick was located on an $\mathrm{MgO}-\mathrm{C}$ sheet of the same composition. The load working on the cylinder when the 
cylinder of the compressive load-testing machine was dropped at a constant speed was measured. The experimental conditions are summarized in Table 1. An MgO-20\%C refractory was used as the brick and sheet material. Mea-

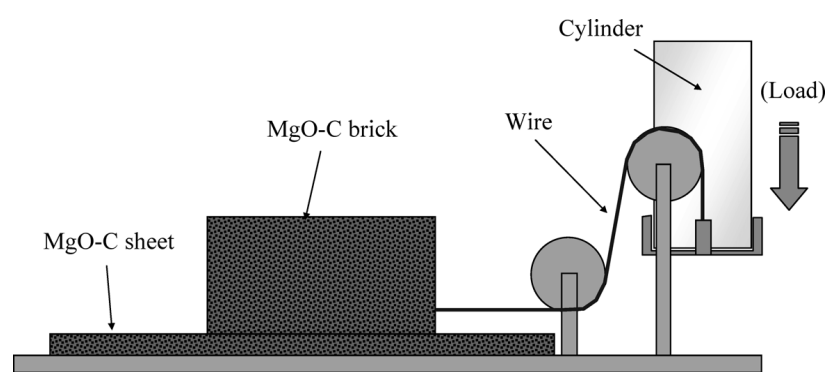

Fig. 1. Experimental apparatus for measurement of friction coefficient.

Table 1. Experimental conditions.

\begin{tabular}{l|c}
\hline Sample material & $\mathrm{MgO}-20 \% \mathrm{C}$ refractory \\
\hline $\begin{array}{l}\text { Weight of material } \\
\text { Stroke }\end{array}$ & $4.0 \mathrm{~kg}$ \\
\hline $\begin{array}{l}\text { Surface condition of } \\
\text { materials }\end{array}$ & Smooth-surfaced $/$ baked /mortar-sticking \\
\hline
\end{tabular}
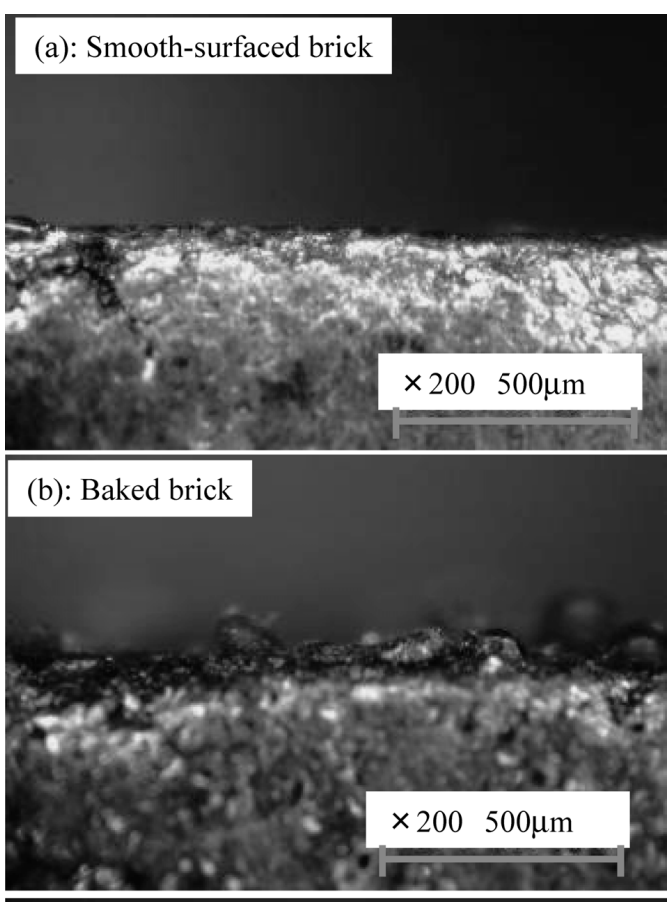

(c): Mortar-sticking brick

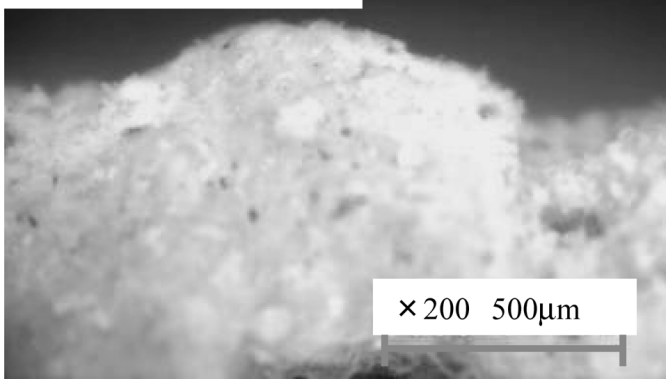

Fig. 2. Photographs of surfaces of bricks ((a): smooth-faced brick, (b): baked brick, (c): mortar-sticking brick). surements were carried out with various surface conditions, i.e., baked brick, mortar-sticking brick, and smooth-surfaced brick. Here, baked brick means a brick that has been heat-treated in a reducing atmosphere and as a result, has a slightly rough surface compared to ordinary bricks. Mortarsticking brick has a rough surface, and smooth-surfaced brick has a smooth surface. Photographs of the surface of each brick are shown in Fig. 2.

\subsection{Experimental Results}

Figure 3 shows an example of the results of the measurements of the friction coefficient. The load was increased linearly, and the $\mathrm{MgO}-\mathrm{C}$ brick on the sheet began to move at a critical load. The brick then continued to move at a constant speed with a constant load. The static friction coefficient was obtained from the value of the peak load (i.e., critical load) using Eq. (1). The dynamic friction coefficient was obtained from the average value after the peak load using Eq. (2) by giving the horizontal distance $x(\mathrm{~m})$ and the weight of brick $m(\mathrm{~kg})$, respectively.

$$
\begin{aligned}
F & =\mu_{0} m g \\
m \frac{d^{2} x}{d t^{2}} & =F-\mu^{\prime} m g=0
\end{aligned}
$$

$\mu_{0}:$ Static friction coefficient

$\mu^{\prime}$ : Dynamic friction coefficient

$F: \quad \operatorname{Load}(\mathrm{N})$

$m$ : Weight of brick (kg)

$g$ : Gravitational acceleration $\left(9.80 \mathrm{~m} / \mathrm{s}^{2}\right)$

The various friction coefficients obtained in the experiment are shown in Table 2. The static friction coefficients were 0.33 with a brick and sheet both having smooth surfaces, 0.52 with a baked brick and baked sheet, 1.53 with a brick

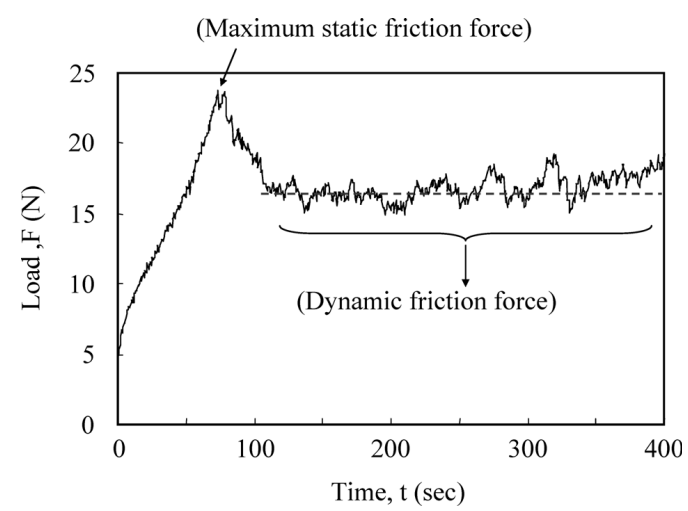

Fig. 3. Examples of changes in load over time.

Table 2. Friction coefficients for various surface conditions.

\begin{tabular}{l|l|l|l}
\hline Condition of brick & Condition of sheet & $\mu_{0}(-)$ & $\mu^{\prime}(-)$ \\
\hline Smooth-surfaced brick & Smooth-surfaced brick & 0.33 & 0.30 \\
\hline Smooth-surfaced brick & Baked brick & 0.30 & 0.26 \\
\hline Baked brick & Baked brick & 0.52 & 0.42 \\
\hline Mortar-sticking brick & Baked brick & 0.59 & 0.53 \\
\hline Mortar-sticking brick & Mortar-sticking brick & 1.53 & 1.25 \\
\hline
\end{tabular}

$\mu_{0}:$ Static friction coefficient

$\mu$ ':Dynamic friction coefficient 
and sheet both having mortar-faced surfaces, and 0.59 with a baked brick and mortar-sticking surface. Yamauchi et al. reported a value of 0.58 as the static friction coefficient between an architectural refractory and mortar, ${ }^{11)}$ which is in good agreement with the result with the mortar-faced brick and baked sheet $(=0.59)$ in this study. On the other hand, the dynamic friction coefficients were 0.30 with the smooth brick and sheet, 0.42 with the baked brick and sheet, 1.3 with the mortar-faced brick and sheet, and 0.5 with the baked brick and mortar-faced surface.

Using these results, a thermal stress analysis was carried out by FEM. Because the brick lining of the converter is dry masonry, the static friction coefficients with smoothsurfaced brick, which was assumed before operation, and the baked brick and sheet, which was assumed after the start of operation, were adopted as the friction coefficients, respectively.

\section{Thermal Stress Analysis}

\subsection{Analytical Conditions}

A thermal stress simulation was carried out based on the lining structure of a converter at JFE Steel West Japan Works (Kurashiki District), as shown schematically in Fig. 4. The analysis was limited to the upper barrel and cone of the converter. An axisymmetrical model was used. First, the thermal distributions of each area in the converter were calculated. A thermal stress simulation was then performed using the temperature distribution results. The following assumptions were applied for the critical conditions:

(1) The lower barrel and bottom of the converter were assumed to form a continuous body.

(2) As the constraint condition for the central axis, only movement in the axial direction (vertical movement) was assumed to be possible.

(3) As the constraint condition for the radial direction, axisymmetry was assumed.

The joint conditions used in this simulation are shown in
Table 3. Calculations were made by three analytical methods, namely, the "contact element", "gap element", and "anisotropy of mechanical property" methods.

In the contact element method, it was assumed that only two bricks are in contact, and compressive and shear stress loading are considered. The effect of friction force on the results of the thermal stress simulation was investigated using this condition by changing the static friction coefficient to zero, 0.3 , or 0.5 . In the gap element method, a virtual gap is assumed between two bricks. When the gap is less than the assumed value, the bricks form a block under stress loading. In this study, the value of the gap was zero, and the modulus of stiffness of the gap was assumed to be infinity (=very rigid) with respect to the vertical and horizontal axes. In addition, the friction coefficient was given as zero or 0.3 because the calculation diverged when the friction coefficient was 0.5 . In the anisotropy method, it was assumed that a virtual joint exists, and the elastic modulus of the joint material changes so as to reduce the contact resistance of the refractory materials in the sliding direction, enabling easy movement. The tangential direction was as-

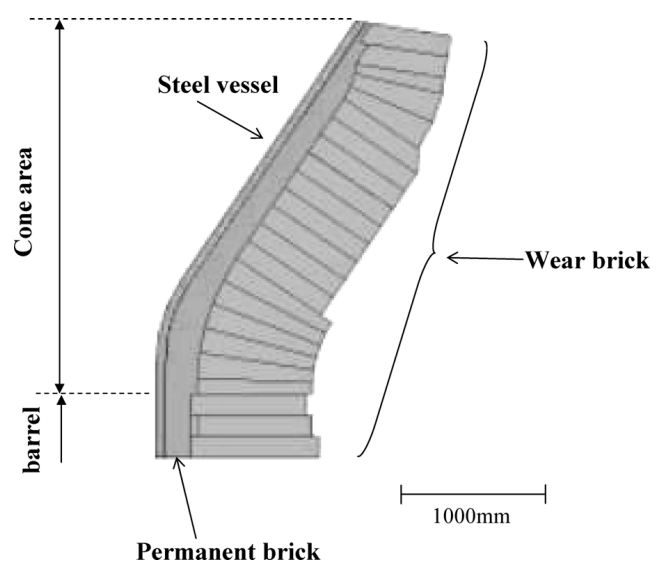

Fig. 4. Schematic diagram of lining structure of converter in cone area.

Table 3. Joint conditions used in this simulation.

\begin{tabular}{|c|c|c|}
\hline Contact element & Gap element & Anisotropy of mechanical property \\
\hline $\begin{array}{l}* \text { Only when two bricks } \\
\text { are in contact, and } \\
\text { compressive and shear } \\
\text { stress loading are } \\
\text { considered } \\
* \text { Tensile stress is not } \\
\text { applied } \\
\text { * static friction coefficient } \\
\mu_{0}=0,0.3 \text { or } 0.5\end{array}$ & 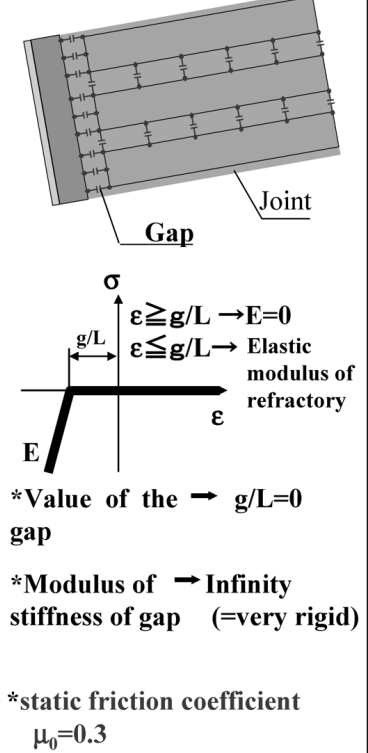 & $\begin{array}{l}\text { *Assumes a virtual joint exists } \\
\text { * Elastic modulus of joint material } \\
\text { changed } \\
\left(\begin{array}{l}\text { so as to reduce the contact } \\
\text { resistance of the refractory } \\
\text { materials in the sliding direction }\end{array}\right) \\
\text { *Main axis:Arrow direction }\end{array}$ \\
\hline
\end{tabular}


sumed to be the main axis. The values of the elastic modulus, Poisson's ratio, and the modulus of rigidity were changed as shown in Table 4. These values were determined by fitting using a trial-and-error method so as to avoid dispersion in the calculated results.

Temperature distributions were calculated by adopting appropriate input heat conditions for each position in the converter (such as metal bath area, freeboard, water quenching area, and surface of vessel quenched by air), as shown in Table 5, assuming thermal resistance would be negligible. The initial temperature was given as $303 \mathrm{~K}$, and an unsteady heat transfer equation was solved numerically by repeating the calculations for $200 \mathrm{~h}$. Thermal properties such as the heat capacity and thermal conductivity were given as shown in Table . $^{12-14)}$

\subsection{Results of Ccalculation}

\subsubsection{Thermal Distribution of BOF}

Figure 5 shows the variation of the calculated temperature at various positions as a function of time. The positions that were considered are the surface of the wear brick, the back side of the wear brick, the back side of the permanent brick, and the surface of the steel vessel. The calculated temperature of each position has clearly become constant

Table 4. Mechanical properties used in anisotropy method.

\begin{tabular}{l|l|l|l}
\hline & $\begin{array}{l}\text { Elastic } \\
\text { modulus E } \\
(\mathrm{GPa})\end{array}$ & $\begin{array}{l}\text { Poisson's } \\
\text { ratio }(-)\end{array}$ & $\begin{array}{l}\text { Modulus of } \\
\text { rigidity, G(GPa) }\end{array}$ \\
\hline $\begin{array}{l}\mathrm{X} \text { axis } \\
\text { (Main axis) }\end{array}$ & $9.81 \times 10^{-4}$ & $3.0 \times 10^{-4}$ & $3.77 \times 10^{-4}$ \\
\hline $\mathrm{Y}$ axis & $9.81 \times 10^{-1}$ & $3.0 \times 10^{-1}$ & $3.77 \times 10^{-1}$ \\
\hline $\mathrm{Z}$ axis & $9.81 \times 10^{-1}$ & $3.0 \times 10^{-4}$ & $3.77 \times 10^{-4}$ \\
\hline
\end{tabular}

Table 5. Interfacial conditions (input heat conditions).

\begin{tabular}{|c|c|c|c|}
\hline & \multicolumn{2}{|c|}{ Input heat transfer condition } & \multirow{2}{*}{ Notes } \\
\cline { 2 - 3 } & $\begin{array}{c}\text { Heat transfer } \\
\text { coefficient, } \alpha\end{array}$ & $\begin{array}{c}\text { Initial } \\
\text { temperature }\end{array}$ & \\
\hline $\begin{array}{c}\text { Free } \\
\text { board }\end{array}$ & $814 \mathrm{~W} \cdot \mathrm{m}^{-2} \cdot \mathrm{K}^{-1}$ & $2073 \mathrm{~K}$ & $\begin{array}{c}\text { Radiation from } \\
\text { molten metal }\end{array}$ \\
\hline $\begin{array}{c}\text { Metal } \\
\text { bath }\end{array}$ & $3488.4 \mathrm{~W} \cdot \mathrm{m}^{-2} \cdot \mathrm{K}^{-1}$ & $1973 \mathrm{~K}$ & $\begin{array}{c}\text { Contact with } \\
\text { molten metal }\end{array}$ \\
\hline Cone & $2093.4 \mathrm{~W} \cdot \mathrm{m}^{-2} \cdot \mathrm{K}^{-1}$ & $313 \mathrm{~K}$ & Water cooling \\
\hline Barrel & $40.7 \mathrm{~W} \cdot \mathrm{m}^{-2} \cdot \mathrm{K}^{-1}$ & $303 \mathrm{~K}$ & Air cooling \\
\hline
\end{tabular}

after $100 \mathrm{~h}$. The temperature of the surface of the steel vessel approached $573 \mathrm{~K}$. Because the measured temperature of the shell surface in actual converters is in the range of $553-603 \mathrm{~K}$, the calculated temperature can be regarded as substantially the same as the observed temperature in actual converters. This consistency is considered to verify the thermal properties used in this calculation and the related assumptions. Therefore, these conditions are also applied in the next step of thermal stress analysis.

\subsubsection{Thermal Stress Analysis}

As mentioned in the introduction, few reports considered friction force in previous studies. First, therefore, the condition in which friction force was not considered was based on the calculations referring to these previous studies, and the effect of friction force on the results of the simulation was investigated. Figure 6 shows the conterminous principal stress distribution in the converter when the maximum static friction coefficient was given as zero, 0.3 , or 0.5 .

The relationship between the minimum principal stress (that is, compressive stress) and the distance from the converter bottom is shown in Fig. 7. In Figures 6 and 7, the ab-

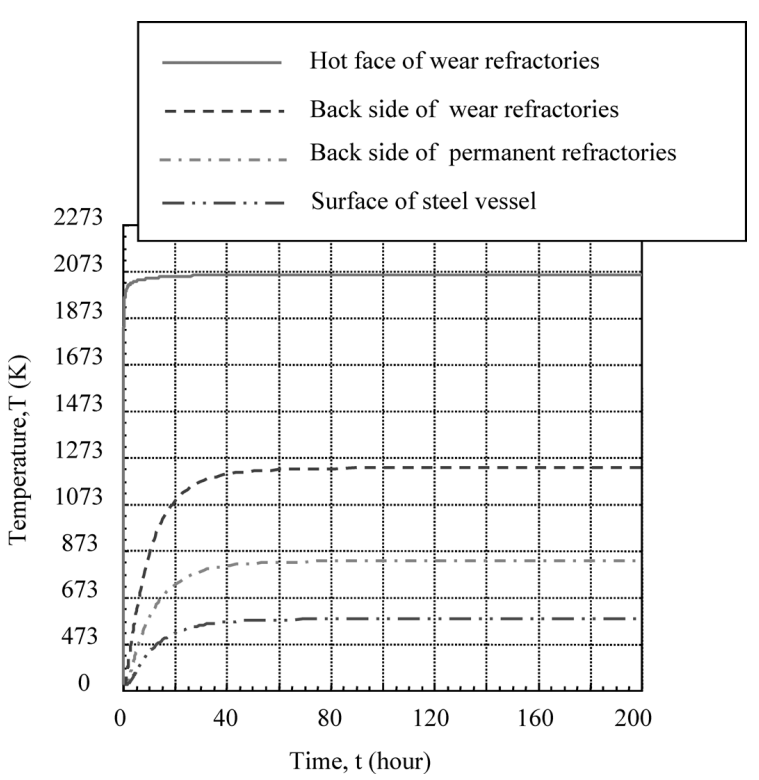

Fig. 5. Time dependency of calculated temperature at surface of wear brick, back side of wear brick, back side of permanent brick, and surface of steel vessel.

Table 6. Thermal properties used in thermal stress analysis.

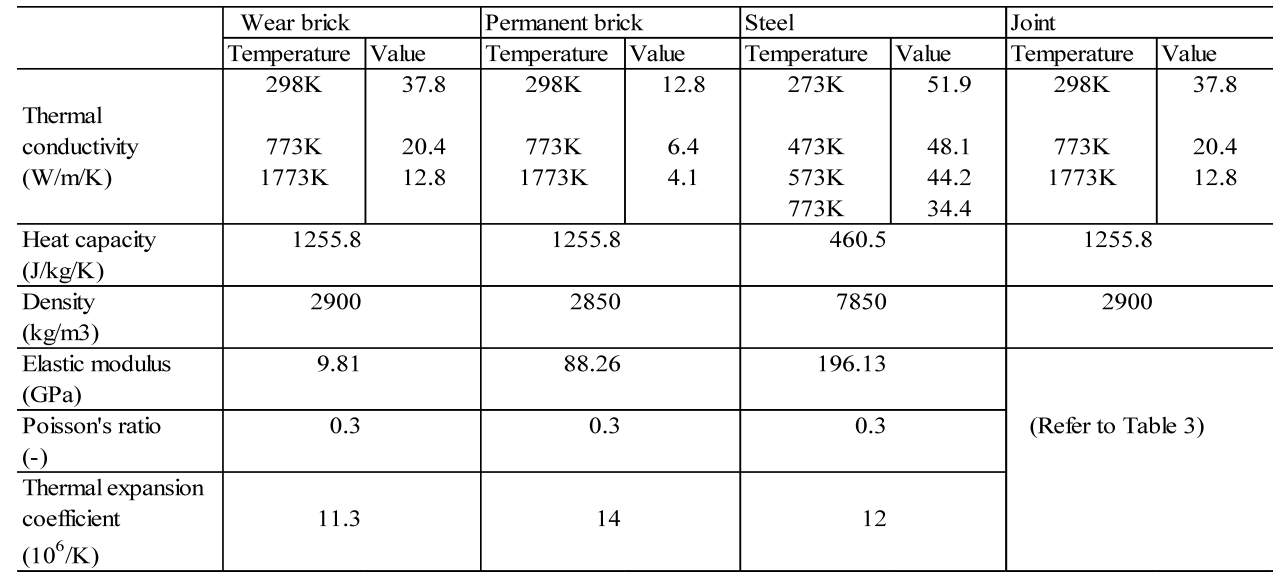




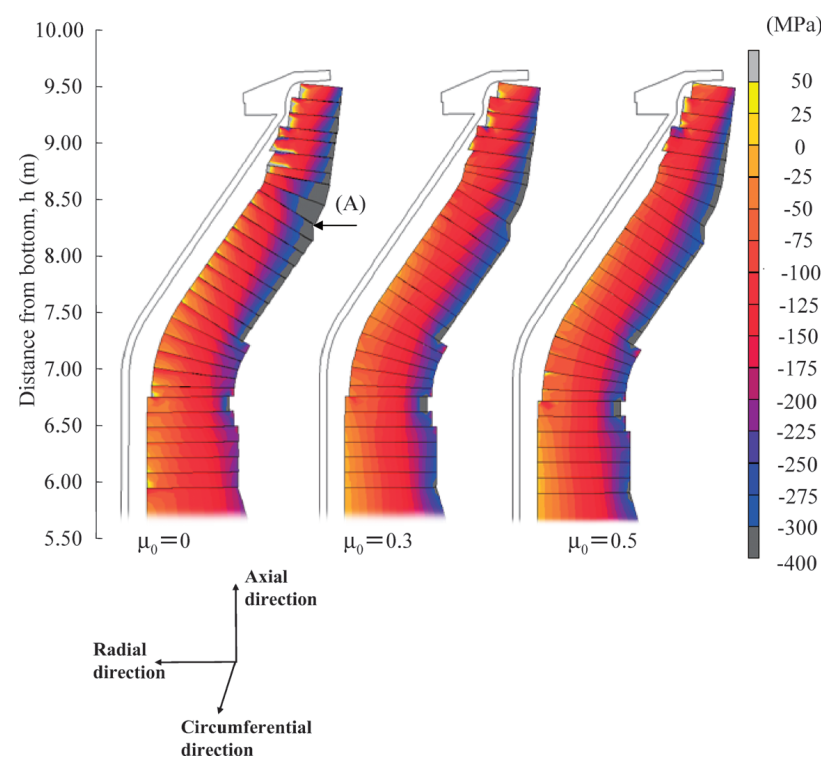

Fig. 6. Conterminous principal stress distribution in converter when static friction coefficient is given as zero, 0.3 or 0.5 .

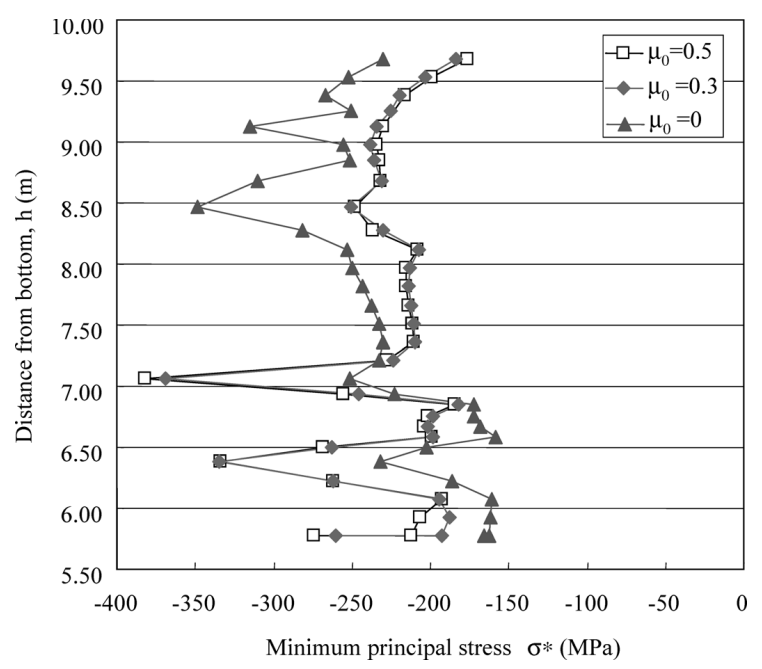

Fig. 7. Relationship between minimum principal stress and distance from converter bottom.

solute value of the stress in this calculation was much larger than the compressive or bending strength of actual refractories because the refractories in these simulations were assumed to be elastic materials. For this reason, all results of the calculations will be discussed as relative comparisons in the following. When the static friction coefficient was 0.3 or 0.5 , the principal stresses were distributed as a linear functional gradient, but when the friction coefficient was zero, stress showed a discontinuous distribution with large differences between the upper and lower sides. This difference is attributed to the fact that a slip phenomenon occurred between the refractories when friction was not considered. As a result, the stress distribution at the upper side of the refractories was different from that at the lower side.

At a distance of $8.5 \mathrm{~m}$ from the converter bottom (indicated by the arrow at point (A) in Fig. 6), much higher compressive thermal stress was generated at the hot face of the refractory brick when the friction coefficient was zero in comparison with that at 0.3 and 0.5 , as shown in Fig. 7.

The calculated result when the friction coefficient was

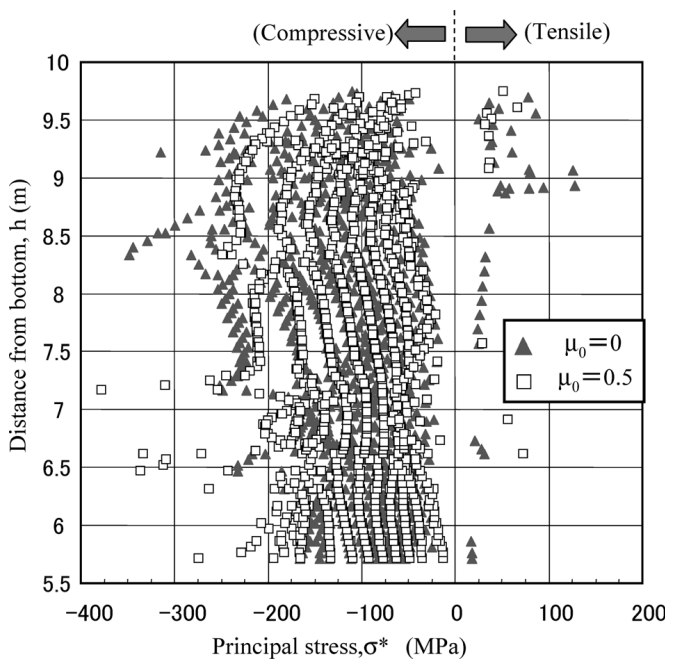

Fig. 8. Relationship between principal stress distribution and distance from converter bottom.

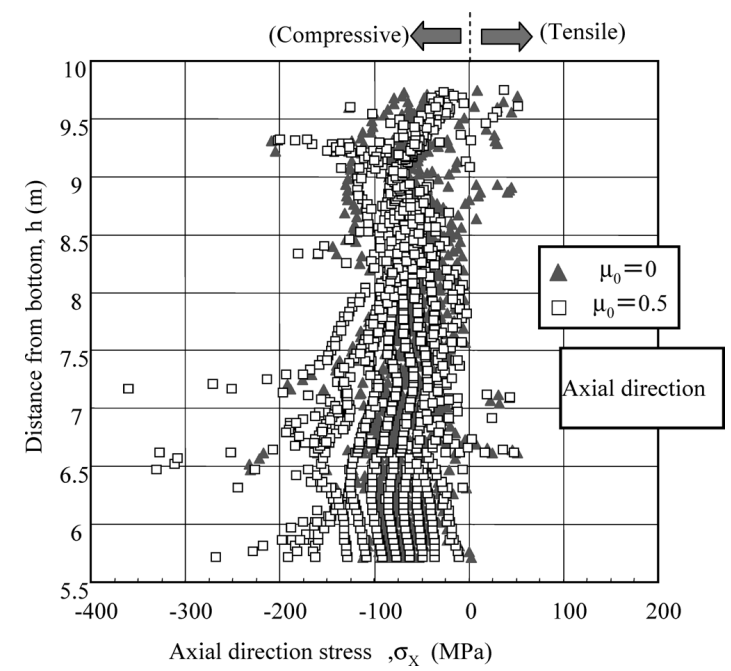

Fig. 9. Relationship between axial stress and distance from converter bottom.

0.3 was similar to that when the friction coefficient was 0.5 . The reason for this phenomenon was considered to be as follows: Under these conditions, the vertical stress which acted on each brick was sufficiently large, and the frictional resistance force was also large. As a result, the difference of displacement between friction coefficients of 0.3 and 0.5 was negligible, and the stress distribution was similar. Therefore, the results of calculations for the case when the friction coefficient is zero will be compared with those when the friction coefficient is 0.5 .

The stress and displacement for the total calculation elements that were divided by the mesh were compared in order to investigate the effect of friction force on the stress and displacement distribution in greater detail. The principal stress distribution is plotted against the distance from the converter bottom as shown Fig. 8. The relationships between the axial, radial, and circumferential stress and the distance from the converter bottom are shown in Figs. 9 to 11, respectively. Here, the axial direction means the height direction from the converter bottom, the radial direction means the horizontal direction from the center axis of the converter, and circumferential direction means the hoop di- 


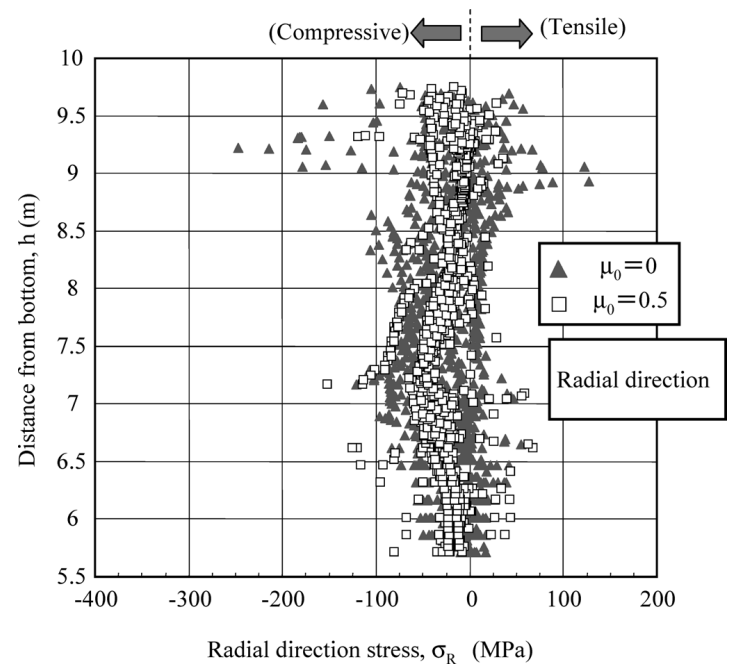

Fig. 10. Relationship between radial stress and distance from converter bottom.

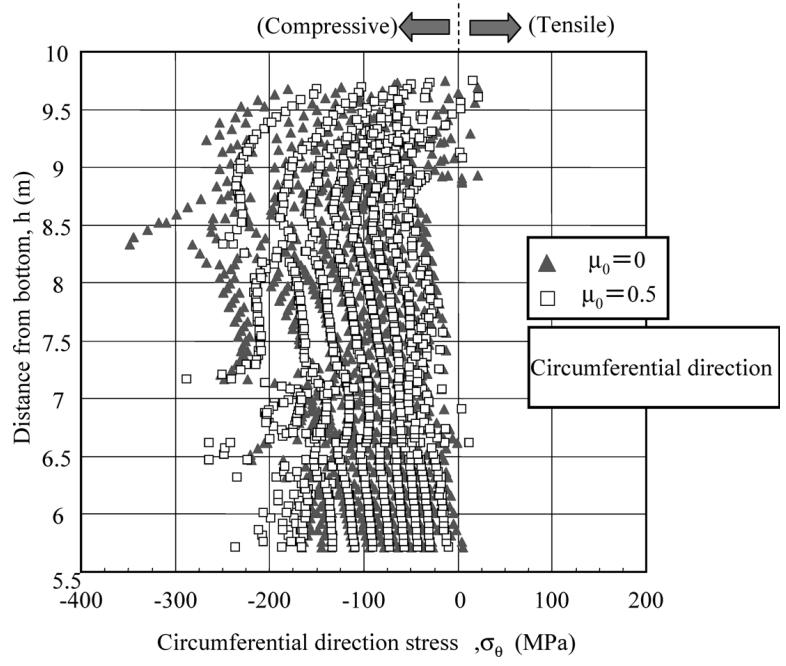

Fig. 11. Relationship between circumferential stress and distance from converter bottom.

rection, that is, the vertical direction for the cross section of the converter in Fig. 4. In Fig. 8, as in Fig. 7, at a distance of $8.5 \mathrm{~m}$ from the converter bottom, much higher compressive thermal stress was generated at the hot face of the refractory brick when the friction coefficient was zero than when the friction coefficient was 0.5 .

The various directional stresses were compared in order to understand which direction requires particular attention. The results for axial stress were obviously similar with the two friction coefficients, as shown in Fig. 9. However, for the radial direction, the calculated difference between the maximum and minimum values of thermal stress when the friction coefficient was zero was larger than that when the friction coefficient was 0.5 (Fig. 10). In addition, much higher compressive thermal stress was generated at the hot face of the refractory brick at a distance of $8.5 \mathrm{~m}$ from the converter bottom when the friction coefficient was zero compared with that at 0.5 . The distribution of principal stress shown in Fig. 8 was almost equivalent to that of circumferential stress, as shown in Fig. 11. Accordingly, circumferential stress should be the focus as the controlling component of principal stress.

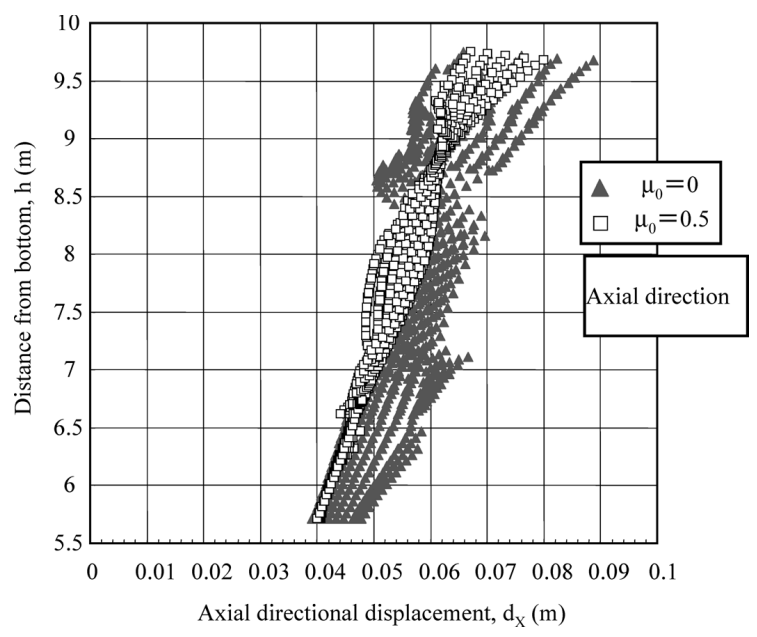

Fig. 12. Relationship between axial displacement and distance from converter bottom.

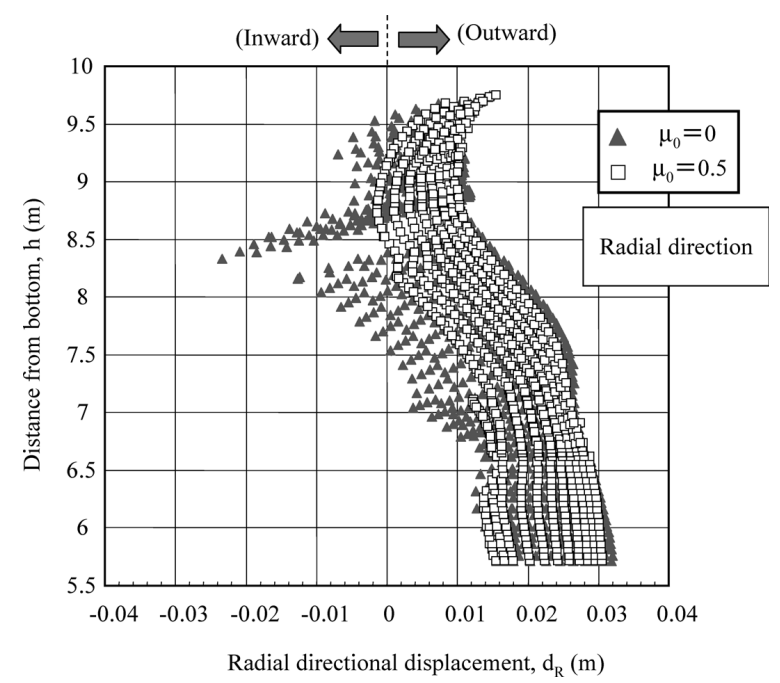

Fig. 13. Relationship between radial displacement and distance from converter bottom.

Axial and radial displacements are plotted against the distance from the converter bottom as shown in Figs. 12 and 13, respectively. Similarly, principal strain is shown in Fig. 14. In Fig. 12, when friction force was not considered, axial displacement increased. In Fig. 13, when friction was not considered, radial displacement increased until around a height of $8 \mathrm{~m}$. The absolute value of radial displacement in the inward direction showed the highest value at this position, where thermal stress was also the highest, as mentioned previously. As a result, principal strain increased locally, limited to the position at a distance of $8.5 \mathrm{~m}$ from the converter bottom, as indicated by the arrow at point (A) in Fig. 6. A comparison of the values of the relative displacement at the position in cone area at point (A) in Fig. 6 is shown in Table 7. The relative displacement corresponds to the difference of displacement between two bricks at point (A). When the friction coefficient was zero, a comparatively large value of displacement was calculated, but when the friction coefficient was 0.5 , relative displacement was zero.

From the above, it was considered that when the relative displacement becomes larger in the inward direction of the converter due to slip, and edge load is generated near the 


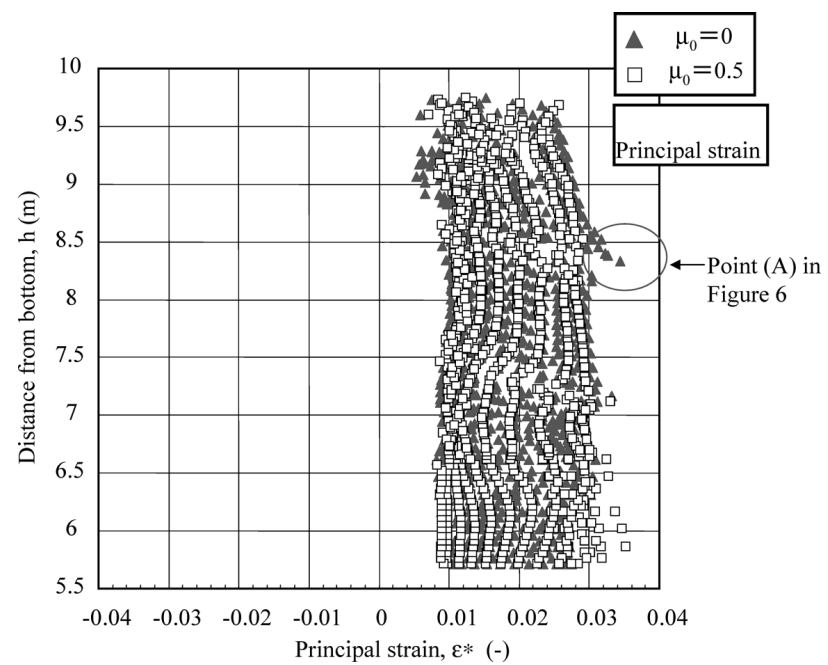

Fig. 14. Relationship between principal strain and distance from converter bottom.

Table 7. Comparison of relative displacement at position in cone area.

\begin{tabular}{|c|c|c|c|}
\hline & \multicolumn{3}{|c|}{ Relative displacement, L [mm] } \\
\cline { 2 - 4 } & $\mu_{0}=0$ & $\mu_{0}=0.3$ & $\mu_{0}=0.5$ \\
\hline $\begin{array}{c}\text { Point (A) } \\
\text { in Figure 6 }\end{array}$ & 7.319 & 0 & 0 \\
\hline
\end{tabular}

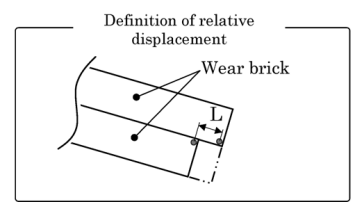

corner of the protruding brick. Next, the higher stress was calculated at this position. However, it should be noted that a condition in which the bricks slip at the position of the cone area in the converter does not occur in actual converters.

Consequently, the simulation revealed that the effect of friction force on the thermal stress analysis was very significant. In particular, concentrated stress at the position of large displacement was found as the key point. Hence, it is essential to take into account the friction force loading between refractories. On the other hand, in actual converters, the condition in which the friction coefficient is 0.3 is limited to the case when the converter is newly started up after relining has been completed, because new bricks with smooth surfaces are installed, but their surface condition changes when the vessel is put into operation. In operation, the wear bricks are baked by the heat of decarburization or post-combustion in the converter. Furthermore, this analysis assumes that these wear bricks are laid with dry masonry. For these reasons, it was considered appropriate to apply the value for baked brick (in this study, 0.5) as the friction coefficient.

Next, the effect of the joint condition on the results was analyzed. Figure 15 shows the conterminous principal stress distribution in the converter. Focusing on a brick in the cone area of the converter (as indicated by the arrow at point (B) in Fig. 15), the distribution of principal stress and

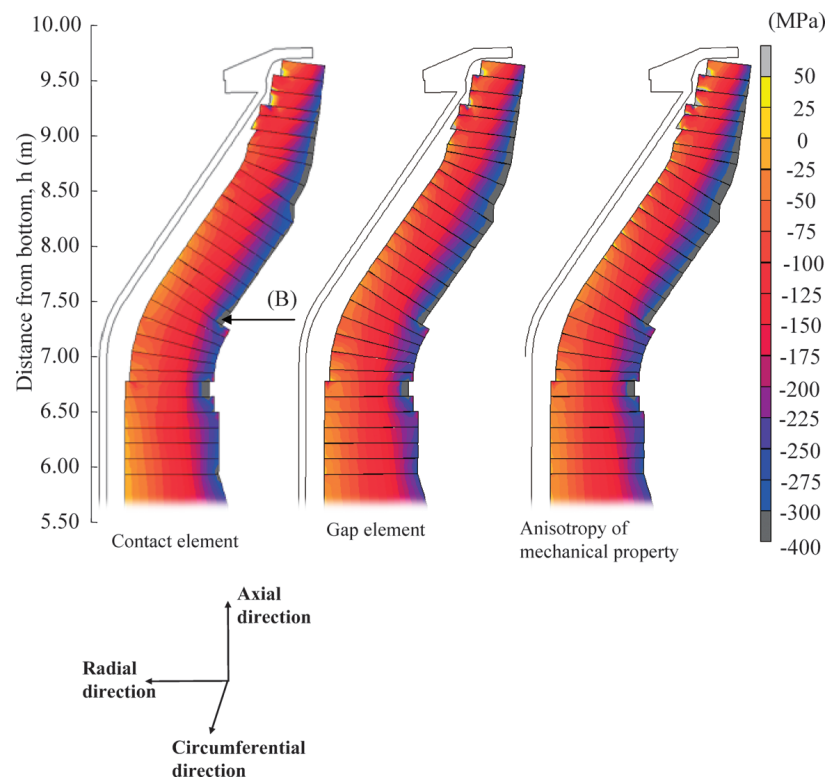

Fig. 15. Conterminous principal stress distribution in converter for each joint condition.

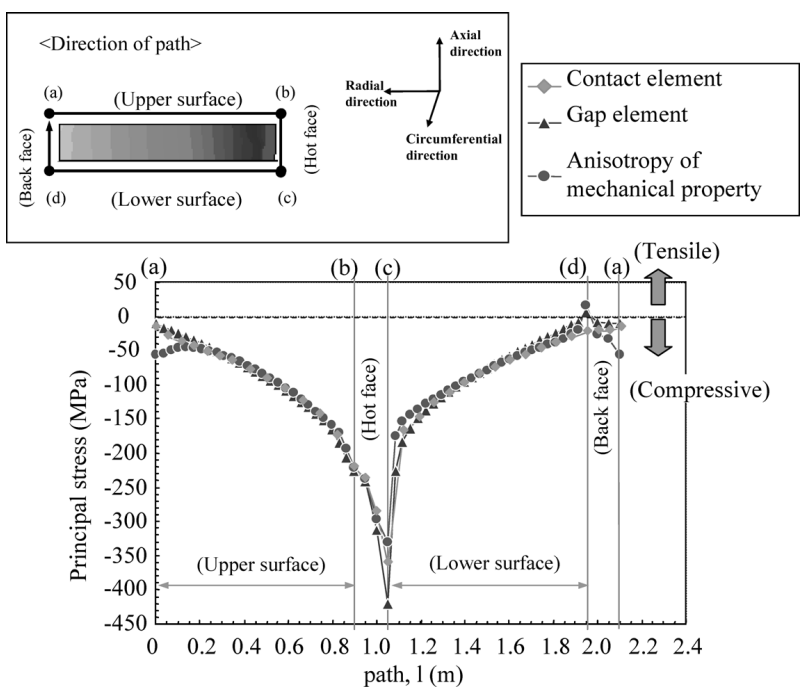

Fig. 16. Relationship between principal stress distribution and surface distance of the brick for each joint condition.

the thermal stresses acting on the brick surface in the axial, radial, and circumferential directions were calculated. The results are shown in Figs. 16 to 19.

The horizontal axis shows the surface distance of the brick, defining the upper edge of the back surface (point (a)) as the starting point. In this study, it has been assumed that the elastic modulus and thermal expansion coefficient are constant, ignoring the temperature dependence of these properties. The temperature distribution in the axial direction is assumed to be substantially constant in the brick. Only the radial direction displays a constant gradient. As a result, the stress distribution could be approximated as symmetrical between the upper and lower surfaces of the brick. Furthermore, when the radial distance of the upper brick was shorter than that of the lower brick, edge load was generated at the lower side of the upper brick. From the above, higher compressive stress was calculated at position (c) in Fig. 16.

In Fig. 16, there are small differences in the principal 


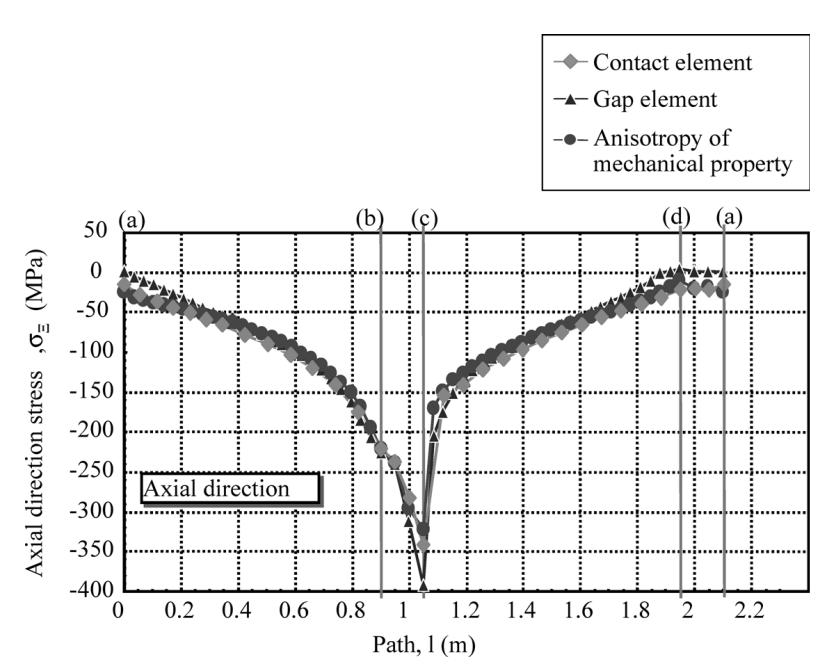

Fig. 17. Relationship between axial stress distribution and surface distance of the brick for each joint condition.

\section{$\rightarrow$ Contact element \\ - - Gap element \\ - Anisotropy of mechanical property}

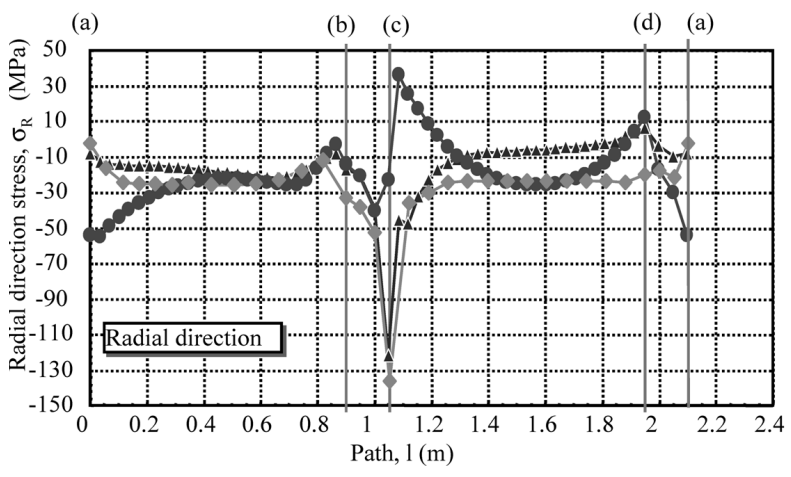

Fig. 18. Relationship between radial stress distribution and surface distance of the brick for each joint condition.

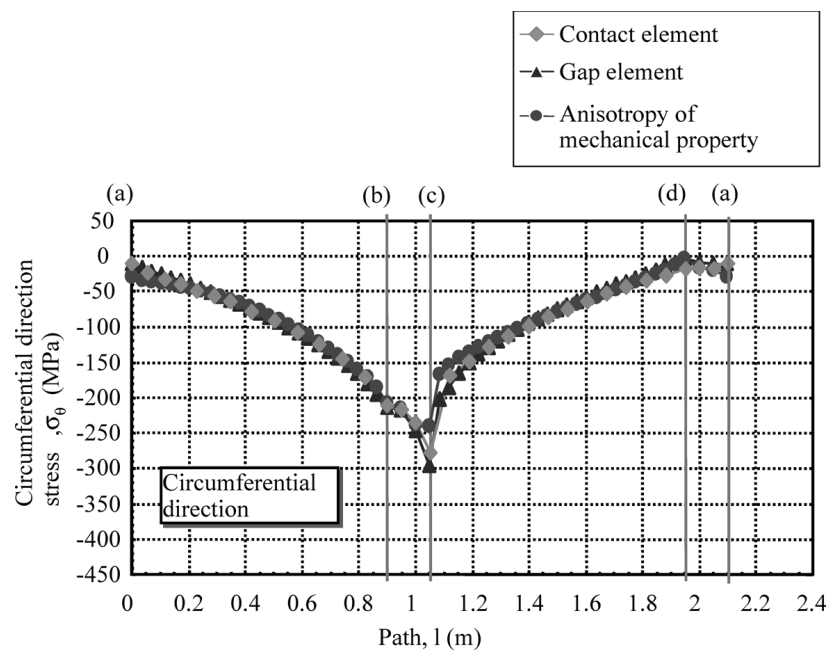

Fig. 19. Relationship between circumferential stress distribution and surface distance of the brick for each joint condition.

stress among these joint conditions, as shown in Table 3. In addition, there are also small differences in axial stress and circumferential stress among these joint conditions. How-
Table 8. Comparison of calculated relative displacement and compressive stress.

\begin{tabular}{c|c|c|c|l}
\hline \multicolumn{2}{l|}{} & Contact element & Gap element & $\begin{array}{l}\text { Anisotropy of } \\
\text { mechanical property }\end{array}$ \\
\hline Displacement & $\mu=0.3$ & 0.0 & 0.0 & 0.218 \\
\hline
\end{tabular}

ever, comparing the contact element analysis to the gap element analysis, the gap element analysis gave a slightly larger difference between the maximum and minimum values of the principal and circumferential stress, as seen in Figs. 16 and 17.

On the other hand, for radial stress, as shown in Fig. 18, the results of the contact element and gap element analyses gave symmetrical distributions for each stress, whereas the anisotropy method gave a non-symmetrical distribution of principal stress. In addition, partial tensile stress was generated because friction force was not taken into account.

Table 8 shows the relative displacement values in the cone area at point (A) in Fig. 6, as simulated with the joint conditions of contact element, gap element, and anisotropy of mechanical property, respectively. From Table 8, the anisotropy of mechanical property without friction force gave a relative displacement of $0.218 \mathrm{~mm}$, while the contact element and gap element with friction force gave a relative displacement of zero. Therefore, the anisotropy of mechanical property method was regarded as not particularly appropriate, based on the fact that brick slippage occurred with this method because friction force was not considered. On the other hand, the difference in the stress distribution calculated using the contact element and gap element as the joint condition was small.

The differences of the mechanism of slip generation and stress transmission between two bricks in contact were examined for the contact element and gap element conditions. Figure 20 shows a schematic diagram of the judgment of contact between two materials and the mechanism of stress transmission in the thermal stress analysis when the joint condition was given as contact element, gap element, or anisotropy of mechanical property, respectively. In the case of contact element, stress transmission included both the positional relationship and the changes caused by slippage of bricks, because the judgment of contact was phase to phase. ${ }^{15)}$ On the other hand, in the case of gap element or anisotropy of mechanical property, stress was transmitted while maintaining the initial positional relationship of the bricks, even after slippage of the bricks occurred, because judgment of contact was made based on point-to-point contact between bricks. ${ }^{15)}$ More specifically, when the joint condition was given as gap element, stress was transmitted while maintaining the same relationship of brick position. In this situation, the direction of stress transmission was calculated as the initial direction of stress transmission, even if displacement of the bricks occurred.

When the friction coefficient is not zero, resistance force acts between the bricks in the direction of the slippage of the bricks, and the relative displacement is small. In this case, the difference between the calculation results by contact element analysis and that by gap element analysis becomes smaller. However, with the gap element method, it is 


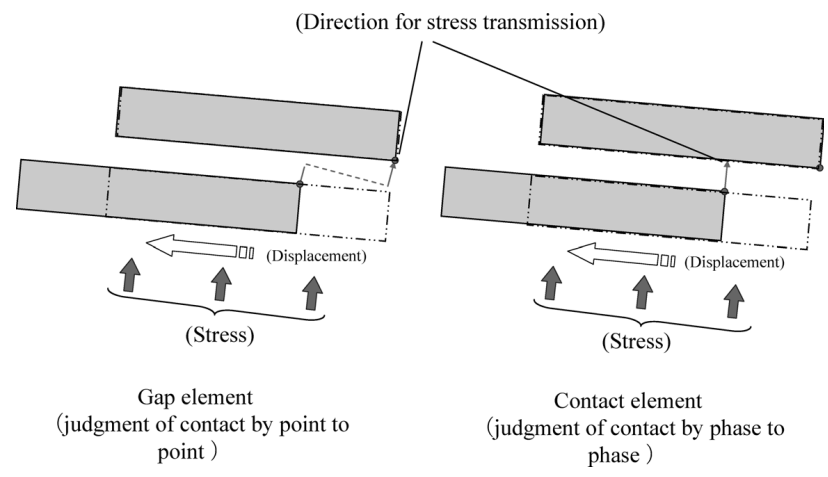

Fig. 20. Schematic diagram showing judgment of contact between two materials and mechanism of stress transmission.

possible to calculate larger stress than with the contact element method, because the direction of stress transmission is calculated as the initial direction of stress transmission even if transformation of the structure has occurred. The above is assumed to be the reason why gap element analysis gave a larger difference between the maximum and minimum values of the principal and circumferential stresses, as seen in Figs. 16 and 17.

Although differing from the main point on this study, if the friction force is negligible and the relative displacement of the bricks is calculated as being large, large error tends to occur in stress calculations. In this case, it is more effective to use contact element as the joint condition for thermal stress analysis.

From the results described above, the effect of friction force on the calculation results in the thermal stress analysis was larger than the effect of the joint condition when the difference in friction force was large. However, considering the relationship of displacement and stress transmission acting on two bricks in contact, applying contact element as the joint condition resulted in an appropriate analysis condition that closely approximated the actual stress transmission phenomenon. Therefore, it can be concluded that the use of contact element as the joint condition was more appropriate than use of gap element.

\section{Summary}

The static friction coefficient and dynamic friction coefficient between $\mathrm{MgO}-\mathrm{C}$ refractories with various surface conditions were measured. The effects of the joint condition and friction force on the thermal stress analysis of the refractory lining in the barrel and cone of the converter were investigated numerically. The results are summarized as follows.

(1) The friction coefficient between refractories was measured for various surface conditions. As a result, a static friction coefficient of 0.52 and a dynamic friction coefficient of 0.42 were obtained for the friction working between the surfaces of baked $\mathrm{MgO}-\mathrm{C}$ refractories, simulating the condition of refractories in the converter after the start of operation.

(2) It is necessary to consider friction force in thermal stress analysis because local abnormal increases in stress occur, corresponding to large displacement of the bricks. Considering the condition of the wear brick in operation, it was appropriate to apply the value obtained with baked brick as the friction coefficient.

(3) The effect of the joint conditions used here, which were contact element, gap element, and anisotropy of mechanical property, on the results of calculations of thermal stress by FEM was comparatively smaller than that of friction force when friction force was considered. If the logic of displacement and stress transmission on two bricks is considered, contact element is appropriate from the viewpoint of stress transmission.

\section{REFERENCES}

1) H. Kawashima, S. Anezaki, S. Yagi, S. Takehara, S. Miyoshi and Y. Fushii: Shinagawa Tech. Rep., 33 (1990), 103.

2) K. Okita, R. Ishikawa, K. Sasaki and Y. Sennou: Taikabutsu, 59 (2007), No. 8, 409.

3) T. Hisanaga, Y. Miyamoto, K. Adachi and K. Aida: Taikabutsu, 60 (2008), No. 2, 106.

4) S. Uchida, M. Satoh, T. Miki and M. Satoh: Taikabutsu, 59 (2007), No. 11,595 .

5) H. Uchida, K. Yamamura and H. Tanno: Taikabutsu, 45 (1993), No. 3,120 .

6) M. Miyahara, K. Toyama, K. Tokimasa and S. Kurihara: J. Mater. Sci., 46 (1997), No. 1, 47.

7) K. Andreev, H. Harmuth, D. Gruber and H. Presslinger: Proc. of UNITECR '03, TARJ, Tokyo, (2003), 564.

8) K. Yamakura, K. Goto and A. Kikuchi: Proc. of UNITECR'03, TARJ, Tokyo, (2003), 384.

9) D. Gruber, K. Andreev and H. Harmuth: Steel Res. Int., 75 (2004), No. 7,455 .

10) A. A. Patuzzi: Iron Steel Eng., (1982), No. 6, 53.

11) N. Yamauchi, Y. Sanada, Y. Nakamura and Y. Nakano: SeisanKenkyu, 58 (2006), No. 6, 497.

12) Refractories Handbook: The Technical Association of Refractories, Japan, (1998), 524.

13) Handbook of Iron and Steel 4th ed., ISIJ, Tokyo, Japan, (2002), 215.

14) M. Masuko: Kikai-Sekkei, Youkendo, Japan, (1988), 160.

15) MSC Marc Users Manual ver. 2003; MSC Software, USA, (2003), Vol. A, No. 8, 12. 